\title{
A New Equivalent Statistical Damage Constitutive Model on Rock Block Mixed Up with Fluid Inclusions
}

\author{
Xiao Chen (iD), Hongfa Xu (D), Hansheng Geng $(\mathbb{D}$, Lu Dong, and Jixiang Zhang \\ State Key Laboratory of Disaster Prevention \& Mitigation of Explosion \& Impact, National Defense Engineering College, \\ Army Engineering University of PLA, Nanjing 210000, China
}

Correspondence should be addressed to Hongfa Xu; xuhongfal@sina.com

Received 31 October 2017; Revised 3 January 2018; Accepted 9 January 2018; Published 18 March 2018

Academic Editor: Michele Brun

Copyright (C) 2018 Xiao Chen et al. This is an open access article distributed under the Creative Commons Attribution License, which permits unrestricted use, distribution, and reproduction in any medium, provided the original work is properly cited.

So far, there are few studies concerning the effect of closed "fluid inclusions" on the macroscopic constitutive relation of deep rock. Fluid-matrix element (FME) is defined based on rock element in statistical damage model. The properties of FME are related to the size of inclusions, fluid properties, and pore pressure. Using FME, the equivalent elastic modulus of rock block containing fluid inclusions is obtained with Eshelby inclusion theory and the double M-T homogenization method. The new statistical damage model of rock is established on the equivalent elastic modulus. Besides, the porosity and confining pressure are important influencing factors of the model. The model reflects the initial damage (void and fluid inclusion) and the macroscopic deformation law of rock, which is an improvement of the traditional statistical damage model. Additionally, the model can not only be consistent with the rock damage experiment date and three-axis compression experiment date of rock containing pore water but also describe the locked-in stress experiment in rock-like material. It is a new fundamental study of the constitutive relation of locked-in stress in deep rock mass.

\section{Introduction}

As the research of rock mechanics gradually develops to deep and complicated geological conditions, the traditional theory of rock mechanics has been continuously improved and perfected. The application of CT technology in rock mechanics helps people have a new understanding of microscopic pore structure of rock, thus establishing a microscopic system of rock [1-4].

Pores are classified into connected pores and closed pores. Actually, the theoretical and experimental research on the connected pores in rock is relatively mature [5-8], and the theory about it has developed to fluid interaction with all forms of subsurface materials, whether the materials are unconsolidated or crystalline [9]. From the perspective of engineering applications, Gassmann-Biot equation describes the relationship between rock physical properties and pore fluid characteristics under the conditions of low frequency [10]. Besides, it is an important theoretical basis of rock fluid replacement or seismic wave detection in oil and gas engineering [11-15]. Compared with the connected pore problems, theoretical and experimental investigations about closed pores are relatively few. Closed pore is an important carrier of locked-in stress. In 1979, the concept of "lockedin" stress was first proposed by Zongji Chen. Based on the microscopic rheological analysis of rock, Chen found that the tectonic loading and thermal loading lead to nonuniform stress field, and some of them are retained in the form of locked-in stress. Additionally, locked-in stress is considered as an important cause of engineering disaster [16]. Barrows considered that the internal shape of viscoelastic Earth material possesses an internal equilibrium pressure over extended periods of geologic time. Internal equilibrium pressure should be regarded as an intrinsic physical property of Earth materials [17]. For a long period of time, the lockedin stress hypothesis has only a few quantitative studies and developments, but the situation has changed in recent years. Wang analyzed the complex environment of diagenesis and the influence of geological processes on the inhomogeneity and discontinuity of rock based on the geological characteristics of rocks [18]. It is also an important source of locked-in stress. Using the hypothesis of locked-in stress, 
Yue proposed and demonstrated that high-pressure fluid inclusions are concrete, measurable, and computational stress inclusions. Besides, they are prevalent in geological rocks and minerals. The effect of fluid inclusions on surrounding rock is calculated. Yue believed that small, confined, and compacted fluid inclusions are common volume stress of rock burst, surrounding rock rupture, and large deformation of roadways in deep rock excavation chambers [19-21].

In general, the research on the constitutive relations of rock fluid inclusions under deep high pressure is very few. Therefore, this study attempts to establish a concise mathematical and physical model that reflects the constitutive relationship between locked-in stress and rock block. The relationship between microcosmic characteristics and macroscopic rules has good applicability, which also lays a good foundation for the mechanical problems of deep rock mass containing closed fluid inclusions.

\section{Related Work}

The statistical damage model is a good mathematical tool for establishing the constitutive relationship between the microscopic and macroscopic properties of rocks. "Rock element" is the basic element of the rock statistical damage model and the "rock element" satisfies the D-P yield criterion. Rock elements gradually yield under external stress, and their strength intensity conforms to Weibull distributions. Moreover, the process can well reflect the stress-strain law of the rock under external stress.

According to the Lemaitre strain equivalence hypothesis, the elastic modulus of rock after damage is as follows [22, 23]:

$$
E_{1}=E_{0}(1-D)
$$

where $E_{0}$ is modulus of elasticity before rock damage, $E_{1}$ is modulus of elasticity after rock damage, and $D$ is damage variable.

The stress-strain curve is consistent with the law of linear elasticity before material damage. The macroscopic constitutive relation considering cumulative damage of rock can be expressed as

$$
\sigma_{1}=E \varepsilon_{1}(1-D)+v_{0}\left(\sigma_{2}+\sigma_{3}\right)
$$

The solution to $D$ is as follows.

According to the study of Wengui Cao, the yield judgment of rock element is appropriate with Drucker-Prager criterion, and the strength intensity of rock elements conforms to Weibull distribution $[24,25]$

$$
F=\frac{\left(\alpha I_{1}+J_{2}{ }^{1 / 2}\right) E \varepsilon_{1}}{\left(\sigma_{1}-2 \mu \sigma_{3}\right)}
$$

where $\alpha$ is the parameter related to cohesion $c$ and internal friction angle $\varphi ; I_{1}$ is the spherical tensor invariant; $J_{2}$ is the deviator tensor invariant; $\alpha=\sin \varphi / \sqrt{9+3 \sin ^{2} \varphi}, I_{1}=\sigma_{1}+$ $\sigma_{2}+\sigma_{3}=\sigma_{1}+2 \sigma_{3}, J_{2}=\left(\sigma_{1}-\sigma_{3}\right)^{2} / 3$.
Assuming that the strength of rock element obeys the Weibull distribution, its probability density function is

$$
P(F)=\frac{m}{F_{0}}\left(\frac{F}{F_{0}}\right)^{m-1} \exp \left[-\left(\frac{F}{F_{0}}\right)^{m}\right],
$$

where $m$ and $F_{0}$ in (4) are Weibull distribution parameters:

$$
D=\int_{0}^{F} P(x) d x=1-\exp \left[-\left(\frac{F}{F_{0}}\right)^{m}\right] .
$$

According to (2), the constitutive relation of rock is as follows:

$$
\sigma_{1}=E_{m} \varepsilon_{1} \exp \left[-\left(\frac{F}{F_{0}}\right)^{m}\right]+2 v_{0} \sigma_{3},
$$

where $\sigma_{3}$ is confining pressure of rock and $E_{m}$ is the elasticity modulus of rock matrix. $F_{0}$ and $m$ can be obtained with value method of multivariate function. It uses the mathematical nature that the derivative of the highest point of the curve is 0 :

$$
\begin{aligned}
& m=\frac{1}{\ln \left[E \varepsilon_{s c} / \sigma_{s c}-2 v_{0} \sigma_{3}\right]}, \\
& F_{0}=F_{s c} m^{1 / m},
\end{aligned}
$$

where

$$
\begin{aligned}
& F_{s c}=\frac{\left[\alpha\left(\sigma_{s c}+2 \sigma_{3}\right)+\left(\sigma_{s c}-\sigma_{3}\right) / \sqrt{3}\right] E \varepsilon_{s c}}{\sigma_{s c}-2 \mu \sigma_{3}} ; \\
& \sigma_{s c}=\frac{2 c \cos \varphi}{1-\sin \varphi}+\frac{1+\sin \varphi}{1-\sin \varphi} \sigma_{3} ; \\
& \varepsilon_{s c}=b+a \sigma_{3} .
\end{aligned}
$$

The parameters $a, b$ in (7) need to be gotten from fitting methods by experiment date and conform to the linear rule.

However, the damage defined in the traditional statistical model essentially reflects the damage caused by the yielding of the nondestructive matrix due to the external stress. Besides, the initial damage of the "fluid inclusions," cracks, and holes existing in the rock before the external loading are not reflected in the model. Obviously, these are important factors influencing the initial elastic modulus of the rock. To establish the relationship between fluid inclusions and macroscopic constitutive relations of rocks, the initial factors of these rocks must be clearly described.

To solve this problem, it is necessary to establish the "rock element" which can reflect the constitutive relation of the rock part representatively, so fluid inclusion-matrix element (FME) is defined [26]. Theoretical basis of FME is RVE, which originates from rock element. Representative volume element (RVE) is an effective method to study such problems, which has been widely used in theoretical and numerical simulation of voids, fractured composites, and so on [27-31]. FME differs from rock element because a typical element of the same size contains a fluid inclusion, and the size is 3 to 5 times of the diameter around the inclusion. There are two types 


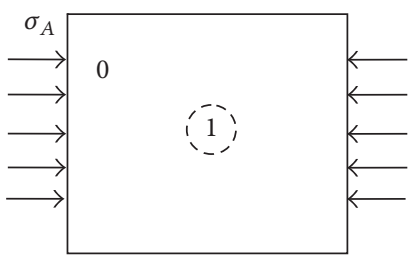

(a)

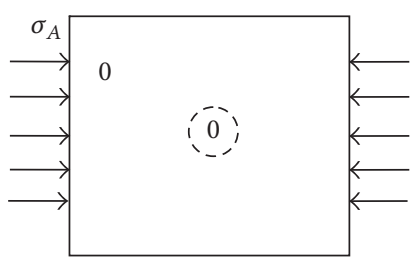

(b)

Figure 1: FME (a) and rock element (b).

of pores in FME. One is connected pore, which indicates that the pore is connected with each other or connected with the cracks in the matrix. This kind of problem includes the pore which has fluid exchange with the outside, whether it has obvious boundary with the matrix or not. It covers the scope of fluid solid coupling, fluid replacement, and other engineering problems. Another kind is the closed pore, which has obvious boundary with matrix or no external exchange of fluid (gas) under certain confining pressure. This kind of FME contains rock pressure existing in the formation of geology, and it is an important carrier of the locked-in stress. Special statement is that pores mixed up with fluid inside FME are collectively referred to as "fluid inclusions" in this study.

\section{Model}

FME is mixed up with a fluid inclusion and rock matrix around a finite range, as shown in Figure 1 ( 0 is matrix; 1 is inclusion).

Figure 1 shows the difference between FME and rock element.

3.1. Fluid Inclusion Volume Modulus of FME. Pore fluid volume modulus of FME $k_{\mathrm{FME}}$ is not only related to porosity but also associated with bulk modulus of fluid $k_{f}$ and bulk modulus of skeleton $k_{m}$. The relationship between $k_{\mathrm{FME}}$ and fluid inclusion compressibility $C_{\mathrm{FME}}$ is as follows:

$$
k_{\mathrm{FME}}=\frac{1}{c_{\mathrm{FME}}} .
$$

$C_{\mathrm{FME}}$ can be expressed as $[32,33]$

$$
c_{\mathrm{FME}}=-\frac{d V_{\mathrm{FME}}}{V_{\mathrm{FME}} d \sigma},
$$

where $V_{\mathrm{FME}}$ is the volume of FME and its rate of volume change is consistent with the overall rate of volume of the rock block $V_{m}$. Therefore,

$$
c_{\mathrm{FME}}=-\frac{d V_{m}}{V_{m} d \sigma} .
$$

The compression factor of rock matrix can be defined as

$$
c_{m}=-\frac{d V_{m}}{V_{m} d \sigma_{m}},
$$

where $\sigma_{m}$ is the stress acting on the rock skeleton. From (12) and (13),

$$
c_{\mathrm{FME}}=-\frac{d V_{m}}{V_{m} d \sigma_{m}} \frac{d \sigma_{m}}{d \sigma}=-\frac{d \sigma_{m}}{d \sigma} c_{m} .
$$

From the point of the whole point of FME, the change of fluid inclusion volume is equal to the volume of fluid. So,

$$
c_{m} d \sigma_{m}=c_{f} d p,
$$

and external stress on the rock $\sigma_{1}$ has the relationship between fluid inclusion pressure $p$ and skeleton pressure $\sigma_{m}$,

$$
\sigma_{1}=\phi p+(1-\phi) \sigma_{m},
$$

where $\phi$ is the ratio of the rock block. Based on (16),

$$
d \sigma=\phi d p+(1-\phi) d \sigma_{m} .
$$

Based on (14) and (17),

$$
\frac{d \sigma_{m}}{d \sigma}=\frac{c_{f}}{(1-\phi) c_{f}+\phi c_{m}} .
$$

From (12) and (17),

$$
c_{\mathrm{FME}}=\frac{c_{f} c_{m}}{(1-\phi) c_{f}+\phi c_{m}} .
$$

From (10) and (19),

$$
k_{\mathrm{FME}}=(1-\phi) k_{m}+\phi k_{f} .
$$

According to the theory of solid mechanics, the compression coefficient of the skeleton under the condition of elastic deformation can be expressed as

$$
k_{m}=\frac{E_{m}}{3\left(1-2 v_{0}\right)},
$$

where $v_{0}$ is Poisson's ratio of the rock matrix. In general, $E_{m}$ is not obtained experimentally, while the overall modulus of matrix elasticity $\left(E_{\text {overall }}\right)$ is experimentally obtained [32]

$$
E_{m}=\frac{E_{\text {overall }}}{1-\varphi} .
$$

In engineering applications, the contents of water, oil, and gas in the fluid inclusions are often different. When there are many kinds of fluid, the effect of fluid components on the fluid inclusion modulus should be considered. In the study of fluid replacement process, Murphy obtained the calculation method of fluid bulk modulus in fluid inclusion under different saturation [34]

$$
\frac{1}{k_{f}}=\frac{S_{W}}{k_{f 1}}+\frac{1-S_{W}}{k_{f 2}},
$$




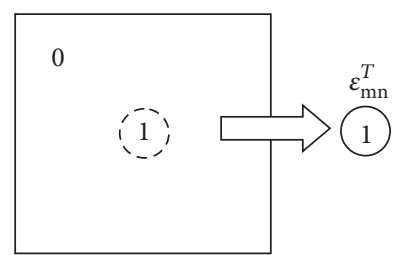

FIGURE 2: FME.

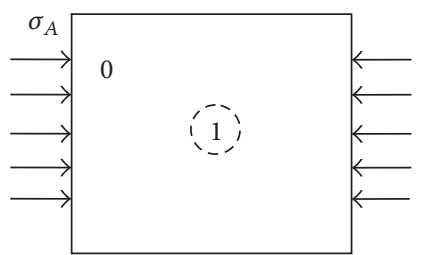

Figure 3: FME under stress. where $S_{W}$ is saturation. $k_{f 1}$ is a fluid volume modulus of fluid inclusion, and $k_{f 2}$ is the second fluid bulk modulus of fluid inclusion. In engineering applications, common reference for determination of fluid elastic parameters is presented in Table 1.

According to Table 1, different fluid or saturation has an important influence on the bulk modulus of elasticity in fluid inclusions. Based on the measured values of Table 1, the volume modulus of elasticity in fluid inclusions includes gas water condition 1.5 3.5 GPa, oil condition $0.9 \sim 2 \mathrm{GPa}$, and water condition $2 \sim 4 \mathrm{GPa}$.

Table 1 is an experiential value used in oil and gas engineering, which is convenient and quick to use. In most cases, there exists a situation that fluid inclusion pressure rather than fluid elastic modulus on rock stress-strain relation is the main consideration. Related researches demonstrate that the fluid inclusion pressure has a positive correlation with the pore compressibility, and the relation between the fluid inclusion volume modulus and the pressure can be depicted as follows [38]:

$$
k_{f}=\beta \Delta p \ln \frac{V_{0}}{V},
$$

where $\Delta p$ is the pressure increment relative to the original pore pressure. $V_{0} / V$ is the ratio of the initial volume to the actual volume of the fluid inclusions in the FME, and $\beta$ is the correction factor under different geological conditions or environment.

Study on compression coefficient or bulk modulus of FME is important for the equivalent elastic modulus based on Eshelby equivalent inclusion theory. It makes the fluid inclusion have practical meaning and physical meaning of certain form, which is different from the traditional solid mechanic problems or traditional inclusion damage model from this point. In addition, it is also a very important reason why this model is suitable to analyze locked-in stress.

3.2. Constitutive Relation of FME. The constitutive relationship of the FME containing different pore types is described by a uniform "equivalent elastic modulus," which is based on the Eshelby equivalent inclusion theory and MT homogenization method. In 1957, Eshelby studied the law of stress around a phase in an infinite homogeneous matrix [39]. Since then, Eshelby equivalent inclusion theory and related analytical solutions have been developed into various forms with wide application in the study of composite and discontinuous medium mechanics [40-47].

As shown in Figure 2, according to the Eshelby inclusion theory, it is firstly assumed that the fluid inclusion in the
FME is homogeneous with the matrix and free from external stress. If the inclusion has a strain $\boldsymbol{\varepsilon}^{\mathbf{T}}$ due to some physical action (thermal expansion, etc.) in unconstrained condition (equivalent to the inclusion gotten from the matrix, as presented in Figure 1), it is called the intrinsic strain. The matrix will produce a bound strain $\boldsymbol{\varepsilon}^{\mathrm{C}}$ on the inclusion due to the existence of intrinsic strain. Eshelby has proved that the relation between intrinsic strain and bound strain is as follows [41]:

$$
\varepsilon^{\mathrm{C}}=\mathrm{S}: \varepsilon^{\mathrm{T}}
$$

where $S_{i j m n}$ is a constant tensor related to the shape of inclusions and the Poisson ratio of the matrix; it is called the Eshelby tensor and (25) can be expressed as

$$
\begin{aligned}
& {\left[\begin{array}{l}
\varepsilon_{11} \\
\varepsilon_{22} \\
\varepsilon_{33} \\
\varepsilon_{12} \\
\varepsilon_{13} \\
\varepsilon_{23}
\end{array}\right]^{C}} \\
& =\left[\begin{array}{llllll}
S_{1111} & S_{1122} & S_{1133} & & \\
S_{2211} & S_{2222} & S_{2233} & & \\
S_{3311} & S_{3322} & S_{3333} & & \\
& & & 2 S_{1212} & & \\
& & & & 2 S_{3131} & \\
& & & & 2 S_{2323}
\end{array}\right]\left[\begin{array}{l}
\varepsilon_{11} \\
\varepsilon_{22} \\
\varepsilon_{33} \\
\varepsilon_{12} \\
\varepsilon_{13} \\
\varepsilon_{23}
\end{array}\right]^{T} .
\end{aligned}
$$
as

If it is a spherical inclusion in FME, $S_{i j m n}$ can be expressed

$$
\begin{aligned}
S_{1111} & =S_{2222}=S_{3333}=\frac{7-5 v_{0}}{15\left(1-v_{0}\right)}, \\
S_{1122} & =S_{2233}=S_{3311}=S_{1133}=S_{2211}=S_{3322} \\
& =\frac{5 v_{0}-1}{15\left(1-v_{0}\right)}, \\
S_{1212} & =S_{2323}=S_{3131}=\frac{4-5 v_{0}}{15\left(1-v_{0}\right)},
\end{aligned}
$$

where $v_{0}$ is matrix Poisson ratio and other tensor projects are 0 .

In fact, the pore fluid inclusions in the FME are heterogeneous with the rock matrix and are subjected to external stress, which can be foundin Figure 3. The strain produced 
TABLE 1: Bulk modulus inside fluid inclusions.

\begin{tabular}{|c|c|c|c|c|c|}
\hline Serial number & $\begin{array}{c}\text { Depth of measuring } \\
\text { point } / \mathrm{m}\end{array}$ & Rock species & fluid inclusion & $\begin{array}{c}\text { Modulus of } \\
\text { elasticity/GPa }\end{array}$ & source \\
\hline \multirow[t]{2}{*}{1} & $1335-1338$ & Sandstone & Gas, water & $1.6 \sim 3.5$ & {$[35]$} \\
\hline & $1430-1438$ & Carbonate & Gas, water & $2 \sim 4$ & {$[35]$} \\
\hline 3 & - & Dolomite & Oil & 1.3 & {$[35]$} \\
\hline 4 & - & Dolomite & Water & 2.6 & {$[35]$} \\
\hline 5 & - & Sand mudstone & Oil & 1.38 & {$[36]$} \\
\hline 6 & - & Sand mudstone & Water & 2.25 & {$[36]$} \\
\hline 7 & $2355-2360$ & Sand mudstone & Water & 2.5 & {$[36]$} \\
\hline 8 & $3206-3210$ & Sand mudstone & $47 \%$ oil $53 \%$ water & $1.8 \sim 4$ & {$[36]$} \\
\hline 9 & $3166-3170$ & Sand mudstone & Oil & $0.9 \sim 2.0$ & {$[36]$} \\
\hline 10 & - & - & Oil & $1.7 \sim 2.4$ & {$[37]$} \\
\hline 11 & - & - & $80 \%$ oil $20 \%$ water & $1.75 \sim 2.3$ & {$[37]$} \\
\hline 12 & - & - & $60 \%$ oil $40 \%$ water & $1.85 \sim 2.2$ & [37] \\
\hline
\end{tabular}

by a heterogeneous inclusion with an external stress can be divided into the following three sections:

(1) Compared with homogeneous material, the perturbation strain tensor produced by the substrate on the heterogeneous inclusions under the action of external stress is $\boldsymbol{\varepsilon}_{\mathrm{e}}$.

(2) Confinement strain tensor of matrix to inclusion is $\boldsymbol{\varepsilon}_{\mathrm{C}}$.

(3) Common strain tensor is $\boldsymbol{\varepsilon}_{\mathbf{A}}$, and it is produced by homogeneous inclusions and matrix due to external stress, conforming to the generalized Hooke's law.

As is shown in Figure 3, the average stress tensor in inclusion is as follows:

$$
\sigma_{1}=\sigma_{\mathrm{A}}+\sigma_{\mathrm{e}}+\sigma_{\mathrm{C}}=\mathrm{E}_{\mathrm{i}}:\left(\varepsilon_{\mathrm{A}}+\varepsilon_{\mathrm{e}}+\varepsilon_{\mathrm{C}}\right),
$$

where $\sigma_{1}$ is total stress tensor of inclusion; $\sigma_{\mathrm{e}}$ is perturbation stress tensor of matrix on inclusion; $\sigma_{\mathrm{c}}$ is the restraint stress tensor of matrix on inclusion; and $\mathbf{E}_{\mathbf{i}}$ is elastic modulus tensor of inclusion.

Average stress tensor of matrix in FME is

$$
\sigma_{0}=\sigma_{\mathrm{a}}+\sigma_{\mathrm{e}}=\mathrm{E}_{\mathrm{m}}:\left(\varepsilon_{\mathrm{A}}+\varepsilon_{\mathrm{e}}\right),
$$

where $\sigma_{0}$ is total inclusion stress tensor; $\mathbf{E}_{\mathbf{m}}$ is elastic constants of matrix.

With Eshelby inclusion theory, (27) can be written as

$$
\sigma_{1}=\mathrm{E}_{\mathrm{i}}:\left(\varepsilon_{\mathrm{A}}+\varepsilon_{\mathrm{e}}+\varepsilon_{\mathrm{C}}\right)=\mathrm{E}_{\mathrm{m}}:\left(\varepsilon_{\mathrm{A}}+\varepsilon_{\mathrm{e}}+\varepsilon_{\mathrm{C}}-\varepsilon_{\mathrm{T}}\right) .
$$

According to the Mori-Tanaka equivalent stress analysis method, the overall mean stress remains unchanged, which can be expressed as [46]

$$
\sigma_{\mathrm{A}}=\varphi \sigma_{1}+(1-\varphi) \sigma_{0},
$$

where $\varphi$ is volume ratio of pore in FME. It depends on $3 \sim 5$ times of fluid inclusion diameter [26].

It can be obtained from (25), (27), and (30) that

$$
\begin{aligned}
& \boldsymbol{\sigma}_{\mathrm{e}}=-\varphi \boldsymbol{\sigma}_{\mathbf{C}}, \\
& \boldsymbol{\varepsilon}_{\mathrm{e}}=-\varphi(\mathbf{S}-\mathbf{I}): \boldsymbol{\varepsilon}_{\mathrm{T}},
\end{aligned}
$$

where I is unit tensor; from (25), (29), and (31),

$$
\begin{aligned}
- & \left\{\mathbf{E}_{\mathbf{m}}+\left(\mathbf{E}_{\mathbf{i}}-\mathbf{E}_{\mathbf{m}}\right):[\varphi \mathbf{I}+(1-\varphi) \mathbf{S}]\right\} \boldsymbol{\varepsilon}_{\mathrm{T}} \\
& =\left(\mathbf{E}_{\mathbf{i}}-\mathbf{E}_{\mathbf{m}}\right): \boldsymbol{\varepsilon}_{\mathbf{A}},
\end{aligned}
$$

and its simple form is

$$
\boldsymbol{\varepsilon}_{\mathrm{T}}=\mathbf{A}^{-1}: \mathbf{B}: \boldsymbol{\varepsilon}_{\mathrm{A}},
$$

where $\mathbf{A}=-\left\{\mathbf{E}_{\mathbf{m}}+\left(\mathbf{E}_{\mathbf{i}}-\mathbf{E}_{\mathbf{m}}\right):[\varphi+(1-\varphi) \mathbf{S}]\right\}, \mathbf{B}=\mathbf{E}_{\mathbf{i}}-\mathbf{E}_{\mathbf{m}}$

Under the action of an external stress tensor $\sigma_{A}$, an average strain tensor $\bar{\varepsilon}$ is generated, which can be obtained in accordance with Hooke's law:

$$
\begin{aligned}
\boldsymbol{\sigma}_{A} & =\overline{\mathbf{E}}: \overline{\boldsymbol{\varepsilon}} \\
& =\overline{\mathbf{E}}:\left[\varphi\left(\boldsymbol{\varepsilon}_{\mathbf{A}}+\boldsymbol{\varepsilon}_{\mathbf{e}}+\boldsymbol{\varepsilon}_{\mathbf{C}}\right)+(1-\varphi)\left(\boldsymbol{\varepsilon}_{\mathbf{A}}+\boldsymbol{\varepsilon}_{\mathbf{e}}\right)\right],
\end{aligned}
$$

where $\overline{\mathbf{E}}$ is equivalent elastic modulus tensor of FME.

From (25), (32), and (34),

$$
\boldsymbol{\sigma}^{\mathbf{A}}=\overline{\mathbf{E}}: \overline{\boldsymbol{\varepsilon}}=\overline{\mathbf{E}}:\left(\boldsymbol{\varepsilon}_{\mathrm{A}}+\varphi \boldsymbol{\varepsilon}_{\mathrm{T}}\right) .
$$

From (33b) and (35),

$$
\overline{\mathbf{E}}=\mathbf{E}_{\mathbf{m}}:\left(\mathbf{I}+\varphi \mathbf{A}^{-1}: \mathbf{B}\right)^{-1} .
$$

3.3. Statistical Damage Model Based on Double M-T Homogenization Theory. The stress-strain relationship of the "fluid inclusions-matrix part" and the "matrix part containing no initial damage" has been obtained. The composition of the rock block is shown in Figure 4.

The stress-strain relationship between the two parts can be unified by the M-T homogenization method [44]. It should be noted that the porosity of rock is $\phi$ and the ratio of the fluid inclusions to the FME mentioned above is $\varphi$. The method of double M-T homogenization method is that the equivalent elastic modulus of FME is considered as an inclusion, and then the equivalent elastic modulus is solved in a wider range 


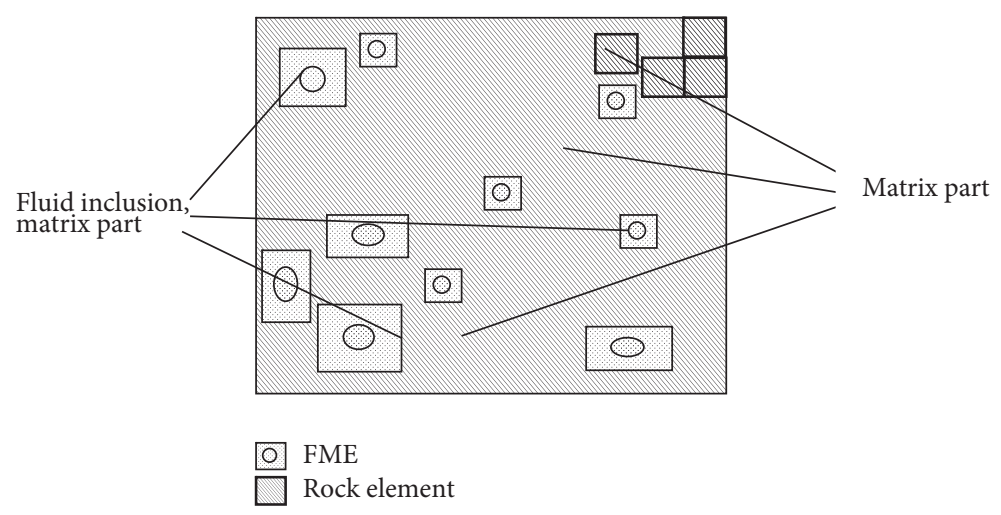

FIGURE 4: FME, rock element, "matrix part," and "fluid inclusion-matrix part."

of rock matrix with FMEs. Therefore, the equivalent elastic modulus of rock block after double M-T homogenization method is

$$
\overline{\overline{\mathbf{E}}}=\frac{\phi}{\varphi} \overline{\mathbf{E}}+\left(1-\frac{\phi}{\varphi}\right) \mathbf{E}_{\mathbf{m}},
$$

where $\overline{\overline{\mathbf{E}}}$ is equivalent elastic modulus tensor of rock matrix based on double M-T homogenization method.

According to (30), (31), (36), and (37), the statistical damage model of the initial fluid inclusions of the rock is expressed as

$$
\begin{aligned}
\boldsymbol{\sigma}_{\mathbf{1}}= & \overline{\overline{\mathbf{E}}}: \boldsymbol{\varepsilon}_{\mathbf{1}} \exp \left[-\left(\frac{F}{F_{0}}\right)^{m}\right]+2 v_{0} \boldsymbol{\sigma}_{\mathbf{3}} \\
= & \exp \left[-\left(\frac{F}{F_{0}}\right)^{m}\right]\left[\frac{\phi}{\varphi} \overline{\mathbf{E}}+\left(1-\frac{\phi}{\varphi}\right) \mathbf{E}_{\mathbf{m}}\right]: \boldsymbol{\varepsilon}_{\mathbf{1}} \\
& +2 v_{0} \boldsymbol{\sigma}_{3},
\end{aligned}
$$

where $\sigma_{1}, \sigma_{3}$ are stress tensors and $\varepsilon_{1}$ is strain tensor.

In this way, the equivalent elastic modulus of FME and the constitutive equation of rock are combined, and the equivalent elastic modulus of FME is closely related to the fluid properties and pressure of fluid inclusions in FME. Then, the relationship between stress-strain curve of rock and fluid inclusions is established.

Numerous studies have demonstrated that rock porosity changes under different confining pressures should be considered. For example, in the study of rock pore seepage process, it was found that the pore porosity will change with the confining pressure. Additionally, the correlation study shows that the porosity changes with the different confining pressure change can be expressed as $[48,49]$

$$
\phi=\phi_{0} e^{-m \sigma_{c}}
$$

where $\phi_{0}$ is initial porosity of rock sample and $m$ reflects the whole process of rock pore changes. The value of $m$ is generally $1 / 10$, which is consistent with the actual situation and can be determined according to the actual change of porosity in the experimental data.
It can be obtained from (32) that

$$
\begin{aligned}
\boldsymbol{\sigma}_{\mathbf{1}}= & \exp \left[-\left(\frac{F}{F_{0}}\right)^{m}\right] \\
& \cdot\left[\frac{\phi_{0} e^{-m \sigma_{c}}}{\varphi} \overline{\mathbf{E}}+\left(1-\frac{\phi_{0} e^{-m \sigma_{c}}}{\varphi}\right) \mathbf{E}_{\mathbf{m}}\right]: \boldsymbol{\varepsilon}_{\mathbf{1}} \\
& +2 v_{0} \boldsymbol{\sigma}_{\mathbf{3}} .
\end{aligned}
$$

If the influence of fluid inclusion pressure of the initial FME on the partial elastic modulus is considered,

$$
\begin{aligned}
\boldsymbol{\sigma}_{\mathbf{1}}= & \exp \left[-\left(\frac{F}{F_{0}}\right)^{m}\right] \\
& \cdot\left[\frac{\phi_{0} e^{-m \sigma_{c}}}{\varphi} \overline{\mathbf{E}}_{\mathbf{H}_{(\Delta \mathbf{p})}}+\left(1-\frac{\phi_{0} e^{-m \sigma_{c}}}{\varphi}\right) \mathbf{E}_{\mathbf{m}}\right]: \boldsymbol{\varepsilon}_{\mathbf{1}} \\
& +2 v_{0} \boldsymbol{\sigma}_{3},
\end{aligned}
$$

where $\overline{\mathbf{E}}_{\mathbf{H}_{(\triangle p)}}$ reflects the effect of pressure on tensor.

According to (41), the effect of porosity on the full stressstrain curve is discussed as follows.

(1) Confining pressure $\sigma_{3}$ is $6.9 \mathrm{MPa}, v_{0}=0.25, E_{m}$ $=90 \mathrm{GPa}$, and $E_{i}=2 \mathrm{GPa}$, internal friction angle of rock $\varphi_{\text {rock }}=31.3039^{\circ}, c=54.89, m=1 / 10, \phi=0.35$ remains unchanged, and $\phi=0.35$ changes with confining pressure.

Figure 5 shows the results. Compared with the situation that the effect of confining pressure on porosity is not considered, the effect of confining pressure on porosity can make the curve more faithfully reflect the strain softening characteristics of rock, and the slope of post-peak curve is steeper. Besides, an important feature of the model lies in the establishment of the relationship between the microscopic and macroscopic rocks. We will confirm whether the model's macroscopic curve is consistent with the true experimental trend of stress-strain curves of rock. Combined with the experimental data of paper [50], the experimental and model data with different confining pressures are compared in later words.

(2) The initial porosity is not mentioned in the reference. When confining pressure is $6.9 \mathrm{MPa}$, the porosity $\phi=0.35$ 


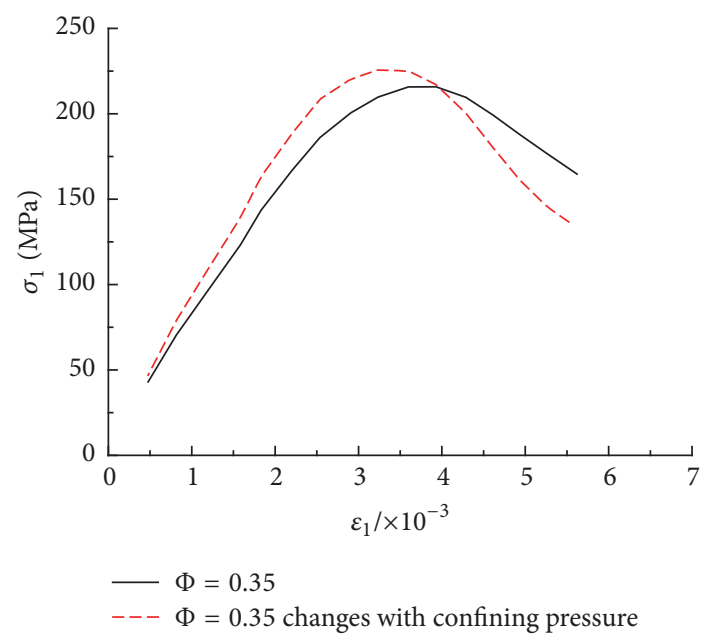

FIGURE 5: Influence of porosity on the full stress-strain curve under confining pressure.

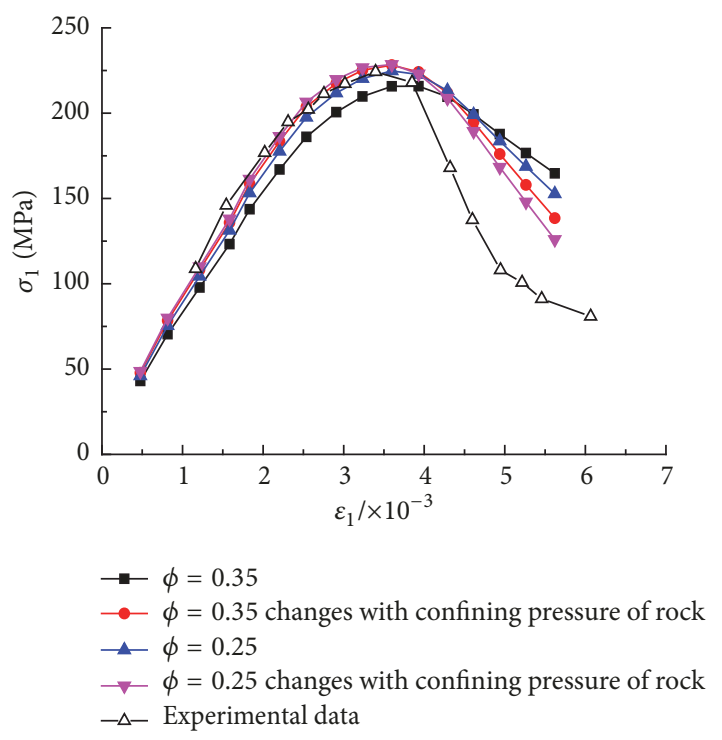

FIGURE 6: Comparison with experimental data; confining pressure is $6.9 \mathrm{MPa}$.

remains unchanged and the initial porosity $\phi=0.35$ changes with confining pressure. Additionally, the porosity $\phi=0.15$ remains unchanged and the initial porosity $\phi=0.15$ changes with confining pressure, $E_{i}=2 \mathrm{GPa}, m=1 / 10$. Results are shown in Figure 6.

(3) When confining pressure is $13.8 \mathrm{MPa}$, the porosity $\phi=0.35$ remains unchanged and the initial porosity $\phi=$ 0.35 changes with confining pressure. The porosity $\phi=0.15$ remains unchanged and the initial porosity $\phi=0.15$ changes with confining pressure, $E_{i}=2 \mathrm{GPa}, m=1 / 10$. Results are shown in Figure 7.

Since the porosity in the original references was not considered or given, two sets of numerical values were selected for simulation. Through comparing Figures 6 and 7 , when the confining pressure is $6.9 \mathrm{MPa}$, the data of $\phi=$ 0.25 is similar to the experimental data. When the confining

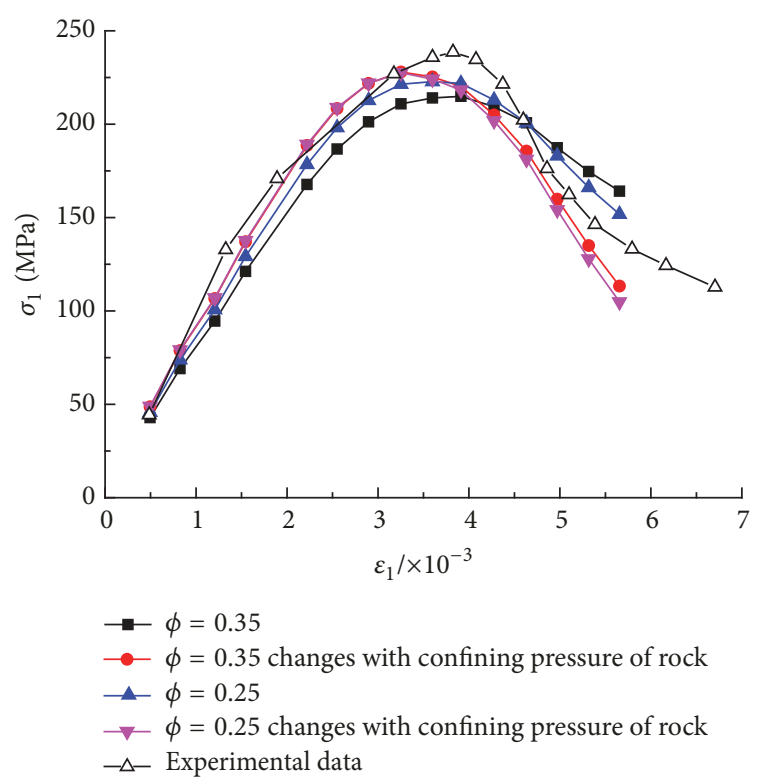

FIGURE 7: Comparison with experimental data; confining pressure is $13.8 \mathrm{MPa}$.

pressure is $13.8 \mathrm{MPa}$, the data of $\phi=0.25$ is similar to the experimental data. Because initial porosities in initial references are not given for different samples, the initial porosity can be assumed for different confining pressures. The model of porosity changing with confining pressure can not only guarantee the accuracy of the variation law before the stress peak but also simulate the law of postpeak variation. It shows the rationality of considering fluid inclusion with confining pressure changing. Besides, there exists the possibility of explaining the influence of FME on the mechanical properties of rock.

Compared with the experimental data of the stressstrain curve, it is reasonable and effective in combining the Eshelby equivalent inclusion theory and the method of statistical mathematics to establish the model. The model has practicality and physical meaning. However, the figure also shows that there is a certain gap between the model curves beyond the yield limit and the development trend of the test curve and that the rock strain softening part is not well modeled. The theoretical establishment of this part is a direction that needs to be conducted in the future.

Meanwhile, on the basis of verification rationality, this model should not only verify the general rock compression experiment, but also validate the rock containing different types of fluid inclusions, especially for the constitutive model of rock mixed up with closed fluid inclusions or locked-in stress. Actually, experimental and verification work in this area is relatively few but significant.

\section{Validation}

Experimental verification includes two types of situations: one is the rock which contains fluid-connected pores and the other is to simulate the rock containing closed pores (lockedin stress) in rock-like materials. 
4.1. Comparison with Experimental Results of Rock Mixed Up with Pore Water (Experimental Verification of the Connected Pore in FME). The influence of the fluid inclusion on the total stress-strain curve of rock is rarely involved in the traditional statistical model of rock damage. In recent years, there are more studies about the influence of fluid inclusion on the overall characteristics of rock. Therefore, in this paper, the rationality of the model is validated by the threeaxis experiment data of rock containing pore water. If the influence of pore pressure variation on the total stress and strain of rock can be obtained, the applicability of the model with the connected pore in FME will be validated.

Through comparing the model with the sample data of rock in $[51,52]$, the unknown parameter is determined by the experimental data at the pore pressure of 0 . At this time, the equivalent elastic modulus of the fluid inclusion is 0 , and the independent variable is few. Based on the two sets of data, the parameters are recognized and corrected, and the unknown parameters of the original text are inversed. Rock parameters are as follows: $E_{m}=14 \mathrm{GPa}, v=0.2$, internal friction angle $\varphi_{\text {rock }}=20^{\circ}$, initial porosity $\phi=0.2, m=1 / 10$.

(1) Fluid inclusion pressure of FME is $4 \mathrm{MPa}$ and confining pressure is $20 \mathrm{MPa}$.

(2) Fluid inclusion pressure of FME is $12 \mathrm{MPa}$ and confining pressure is $20 \mathrm{MPa}$.

Figures 8 and 9 show that the model data is in good agreement with the experimental data of rock containing pore water. Before reaching the yield limit of the rock, the model basically agrees with the experimental data of rock containing pore water. Additionally, the model can simulate the law of full stress and strain and reflect the influence of pore water in FME on the total stress and strain of rock. That is to say, the relationship between the different pore water or the fluid state in the pore and the macroscopic characteristics of the rock can be analyzed using the model. Therefore, the model has practicality in analyzing rock mechanics problems with connected pore with an advantage in back analysis of pore properties through macroscopic phenomena.

4.2. Comparison with the Test Results of the Locked-In Stress in Rock (Experimental Validation of the Closed Pore in FME). If the fluid state in FME can be reasonably reflected, the model not only can be used to analyze the rock block containing connected pores, but also has good applicability to the rock containing locked-in stress. However, the experimental researches about locked-in stress are few, and the experimental simulation itself is also confronted with a lot of difficulties. The change of equivalent fluid inclusion modulus of FME has mature application in fluid replacement in oil and gas engineering, while the experimental date about the constitutive relation of rock in this process is few. Consequently, in this part, the locked-in stress in rock is validated by simulating the closed pores with different equivalent modulus of elasticity in FME.

The experiment is designed that nitrile rubber inside rock matrix (rock-like material) can produce different expansion pressure at different temperature control conditions to simulate the different locked-in stress in rock. The equivalent

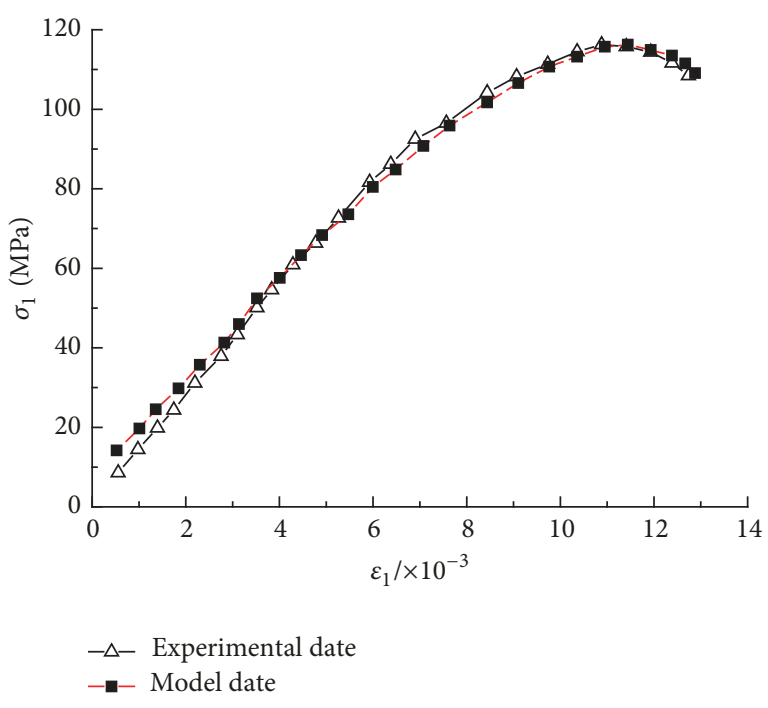

FIGURE 8: Comparison between experimental date and model date; fluid inclusion pressure of FME is $4 \mathrm{MPa}$; confining pressure is $20 \mathrm{MPa}$.

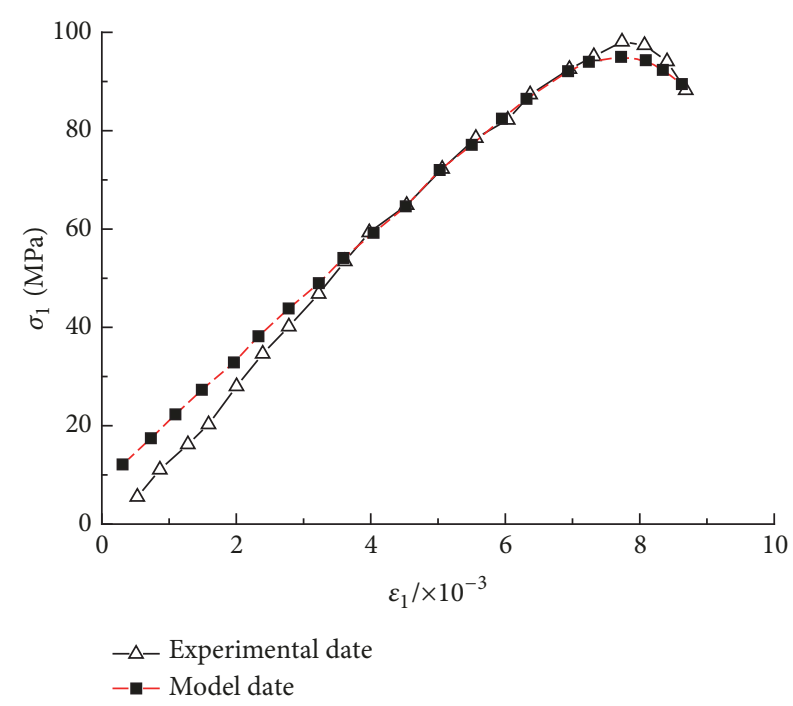

FIGURE 9: Comparison between experimental date and model date; fluid inclusion pressure of FME is $12 \mathrm{MPa}$; confining pressure is $20 \mathrm{MPa}$.

elastic modulus of different inclusions in FME can be achieved from the above analysis. Besides, the matrix material consists of Portland cement and fine quartz sand in a certain proportion. The parameters are as follows: $E_{m}=2.5 \mathrm{GPa}$, $E_{0}=0.2 \mathrm{GPa}, v_{0}=0.25$, internal friction angle $\varphi_{\text {rock }}=$ $0.25, c=50 \mathrm{MPa}$, and $\sigma_{3}=0$. The experimental data of pore rubber materials were $2 \%$ and $4 \%$ respectively, and the locked-in stress was $0.8 \mathrm{MPa}$ and $1.2 \mathrm{MPa}$, respectively. The transformation relationship between date of experimental situation and theoretical transformation value is presented in Table 2.

Figure 10 shows the result of the situation that porosity is $2 \%$ and equivalent elastic modulus of fluid inclusion is 
TABLE 2: Transformation relationship.

Experimental situation $\quad$ Proportion of rubber material in matrix:

Theoretical transformation value $2 \% / 4 \%$ rosity: $2 \% / 4 \%$
Locked-in stress: $0.8 \mathrm{MPa} / 1.2 \mathrm{MPa}$

Equivalent elastic modulus of fluid inclusion: $0.2 \mathrm{GPa} / 0.5 \mathrm{Gpa}$
$0.5 \mathrm{GPa}$. Figure 11 shows the result of the situation that porosity is $4 \%$ and equivalent elastic modulus of fluid inclusion is $0.2 \mathrm{GPa}$.

The locked-in stress exerts significant influence on the experiment. The data in Figures 10 and 11 shows that the model curve reflects the change law before and after the peak in the actual experiment. Additionally, the random error control is within a certain range. However, it is undeniable that there is a certain difference between the model curve and the final part of the test date. Therefore, there are factors affecting the curve changes which have not been fully taken into consideration.

Therefore, from the experimental verification results of this part, it can be seen that the influence of locked-in stress in the deep rock mass on the macroscopic constitutive relationship should not be ignored. High-pressure and high-energy fluid inclusions in deep rock mass are the important reasons for such phenomena as rock burst and large deformation. Based on the model, we can analyze the fluid inclusions in the deep rock mass to predict or analyze some rock phenomenon. Additionally, the model provides a new idea for the solution of deep rock mechanics problems.

\section{Conclusions}

With the development of deep rock mechanics, more and more attention has been paid to the locked-in stress in rocks. High-pressure fluid inclusions are important parts of the locked-in stress in deep rock mass. Nevertheless, there are few studies on the mechanical properties of rock mixed up with closed pores. Based on RVE, this paper unifies the analysis methods of closed pore and connected pore, and FME is defined. Based on FME, the relationship between the microscopic fluid inclusions and the macroscopic mechanical properties of the rock is established using the statistical mathematical method.

The main works of this paper are as follows: on the basis of the traditional damage model, firstly, the constitutive relation of FME is built on Eshelby equivalent inclusions theory, and the stress-strain relation of FME is then determined. Secondly, the influence of FME on initial modulus of elasticity of rock mass is analyzed and the relationship between FME and the whole stress and strain of the matrix is established based on the Weibull distribution. The effect of fluid inclusions in FME on the stress-strain curve of rock is analyzed. Compared with the general rock compression experimental data, the model is proved to be reasonable. On this basis, the model is compared with the three-axis confining pressure experimental date and locked-in stress simulation experiment of rock mass. Moreover, the model results are in good agreement with experimental date.

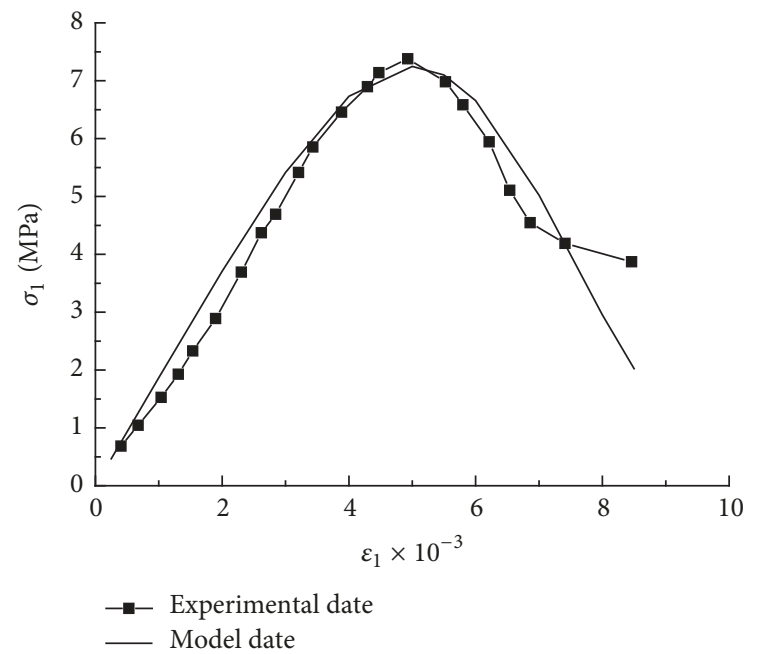

FIGURE 10: Comparison between experimental date and model date and fluid inclusion pressure of FME is $0.8 \mathrm{MPa}$.

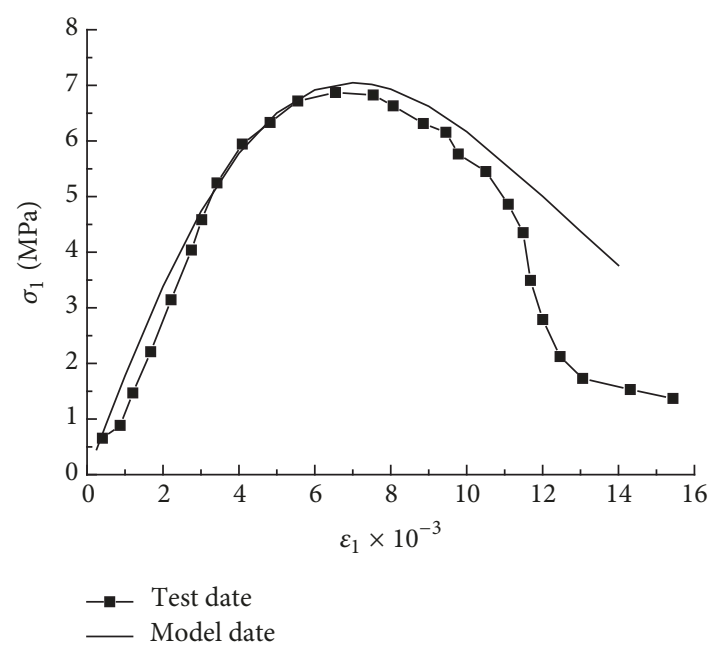

FIGURE 11: Comparison between experimental date and model date; fluid inclusion pressure of FME is 1.2 MPa.

The main conclusions are as follows:

(1) FME is the medium of establishing the fluid inclusion and macroscopic stress-strain curve of rock. Combined with the principle of Eshelby equivalent inclusion, the FME can reflect the fluid state of the fluid inclusion and other factors with the concept of equivalent elastic modulus. FME is a basis of rock statistical damage model. It is an improvement of the traditional statistical damage model which cannot effectively reflect the initial fluid inclusion, crack, and other damage. 
(2) The stress of the same strain changes with the increasing elastic modulus of the FME, but it does not influence the variation trend before and after the peak. However, the increase of porosity affects the gradient of the curve behind the peak, and the stress-strain curve becomes slow with the increase of porosity. The assumption that porosity varies with confining pressure can reflect the law of post-peak variation, which is greatly consistent with the experimental data.

(3) Compared with the different experimental data, the model based on FME and the mathematical statistics model is reasonable. Based on FME, it can reflect the influence of initial porosity or initial damage in a wider sense on rock mechanical properties, whether it is connected pore or closed pore in FME. As long as the initial damage can be reflected in FME, the influence of initial damage can be obtained from the model.

The innovations of the model are as follows:

(1) Using the Eshelby equivalent inclusion theory and M-T uniform theory, the initial elastic modulus of rock is analyzed. Besides, it is an improvement of the traditional damage model, which cannot reflect the initial hole and damage of the rock, making the new statistical damage model more practical and reasonable.

(2) Based on FME, the relationship between rock microcosmic and macroscopic is established. The macroscopic constitutive relation of rock is analyzed by fluid inclusions in FME. Few studies have been conducted from this point of view.

(3) The model is employed to analyze the locked-in stress in deep rock mass, and the locked-in stress simulation experiment is carried out, which is groundbreaking for analyzing geological phenomena through the point of lockedin stress. Briefly, one important reason why we call it a new model is the effect of the locked-in stress on the rock. Therefore, the mathematical statistics model built on it is reasonable and effective.

\section{Conflicts of Interest}

The authors declare that there are no conflicts of interest regarding the publication of this paper.

\section{Acknowledgments}

The authors acknowledge the support of Jiangsu Natural Science Foundation of China (BK20141067).

\section{References}

[1] M. Vervoot, M. Wevers, R. Swennen et al., "Recent advances of $\mathrm{X}$-ray CT and its application for rock material," in Proceedings of the X-ray CT for Geomaterials; Soils, Concrete, Rocks, 2004.

[2] L. Du, X. Zhang, J. Niu, X. Wang, and G. Feng, "The seismic CT method in measuring rock bodies," Applied Geophysics, vol. 3, no. 3, pp. 192-195, 2006.

[3] D. Crandall, G. Bromhal, and D. H. Smith, "Conversion of a micro-CT scanned rock fracture into a useful model," in Proceedings of the 2009 ASME Fluids Engineering Division
Summer Conference, FEDSM2009, pp. 2101-2108, USA, August 2009.

[4] A. Sato and T. Mukunoki, "Fundamental Knowledge of X-ray CT and Its Application to Rock Engineering," Journal of MMIJ, vol. 131, no. 6, pp. 277-284, 2015.

[5] G. Molli, G. Cortecci, L. Vaselli et al., "Fault zone structure and fluid-rock interaction of a high angle normal fault in Carrara marble (NW Tuscany, Italy)," Journal of Structural Geology, vol. 32, no. 9, pp. 1334-1348, 2010.

[6] B. E. Treeby and B. T. Cox, "k-Wave: MATLAB toolbox for the simulation and reconstruction of photoacoustic wave fields," Journal of Biomedical Optics, vol. 15, no. 2, Article ID 021314, 2010.

[7] R. Klemd, "High-pressure fluid-rock interaction as the cause of bulk rock compositional changes in blueschists and eclogites," Egu General Assembly, vol. 14, no. 3980, 2012.

[8] X. Zhuang, R. Huang, C. Liang, and T. Rabczuk, "A coupled thermo-hydro-mechanical model of jointed hard rock for compressed air energy storage," Mathematical Problems in Engineering, vol. 2014, Article ID 179169, 11 pages, 2014.

[9] C. I. Steefel and K. Mäher, "Fluid-rock interaction: A reactive transport approach," Reviews in Mineralogy and Geochemistry, vol. 70, no. 1, pp. 485-532, 2009.

[10] F. Gassmann, "Elastic waves through a packing of spheres," Geophysics, vol. 16, no. 4, pp. 673-685, 1951.

[11] B. H. Russell, K. Hedlin, F. J. Hilterman, and L. R. Lines, "Fluid-property discrimination with AVO: A Biot-Gassmann perspective," Geophysics, vol. 68, no. 1, pp. 29-39, 2003.

[12] J. M. Carcione, B. Gurevich, and F. Cavallini, "A generalized Biot-Gassmann model for the acoustic properties of shaley sandstones," Geophysical Prospecting, vol. 48, no. 3, pp. 539-557, 2000.

[13] Z. Hou, C. Guo, and J. Wang, "Using Gassmann Equation Predict Marine Sediment Porosity," Earth Science, 2016.

[14] J.-Y. Li, "Gas reservoir identification by seismic AVO attributes on fluid substitution," Applied Geophysics, vol. 9, no. 2, pp. 139148,2012

[15] N. Tisato, C. Madonna, and S. Boutareaud, "A new instrumentation to measure seismic waves attenuation," in Proceedings of the AGU Fall Meeting, 2010, AGU Fall Meeting Abstracts.

[16] T. K. Tan, "On the locked in stress, creep and dilataion of rocks and the constitutive equations," Chinese Journal of Rock Mechanics Engineering, 1991.

[17] L. Barrows, "Locked-in stress in viscoelastic Earth materials," Eos, Transactions, American Geophysical Union, vol. 78, no. 24, p. 248, 1997.

[18] S. Wang, "Geological nature of rock and its deduction for rock mechanics," Chinese Journal of Rock Mechanics and Engineering, vol. 28, no. 3, pp. 433-450, 2009.

[19] Z. Q. Yue, "Gas inclusion and their expansion power as foundation of rock locked in stress hypothesis," Journal of Engineering Geology, vol. 22, no. 4, pp. 739-756, 2014.

[20] Z. Q. Yue, "On nature of earthquakes with cause of compressed methane gas expansion and migration in crustal rocks," in Proceedings of the 5th Biot Conference on Poromechanics, BIOT 2013, pp. 507-516, Austria, July 2013.

[21] Z. Q. Yue, "On cause hypotheses of earthquakes with external tectonic plate and/or internal dense gas loadings," Acta Mechanica, vol. 225, no. 4-5, pp. 1447-1469, 2014.

[22] J. Lemaitre, "A continuous damage mechanics model for ductile fracture," Journal of Engineering Materials and Technology, vol. 107, no. 1, pp. 83-89, 1985. 
[23] J. A. Lemaitre, "How to use damage mechanics," Nuclear Engineering and Design, vol. 80, no. 2, pp. 233-245, 1984.

[24] W. Cao, M. Zhao, and C. Liu, "Study on the model and its modifying method for rock softening and damage based on Weibull random distribution," Chinese Journal of Rock Mechanics and Engineering, vol. 23, no. 19, pp. 3226-3231, 2004.

[25] W.-G. Cao and X. Li, "A new discussion on damage softening statistical constitutive model for rocks and method for determining its parameters," Rock and Soil Mechanics, vol. 29, no. 11, pp. 2952-2956, 2008.

[26] H. Xu, X. Chen, L. Dong, and Y. Yang, "Equivalent Elastic Constants of Rock Containing Pore Fluid Inclusions," Journal of Basic Science and Engineering, vol. 25, no. 2, pp. 369-381, 2017.

[27] Z. F. Khisaeva and M. Ostoja-Starzewski, "On the size of RVE in finite elasticity of random composites," Journal of Elasticity, vol. 85, no. 2, pp. 153-173, 2006.

[28] S. I. Ranganathan and M. Ostoja-Starzewski, "Scaling function, anisotropy and the size of RVE in elastic random polycrystals," Journal of the Mechanics and Physics of Solids, vol. 56, no. 9, pp. 2773-2791, 2008.

[29] M. Ostoja-Starzewski, X. Du, Z. F. Khisaeva, and W. Li, "Comparisons of the size of the representative volume element in elastic, plastic, thermoelastic, and permeable random microstructures," International Journal for Multiscale Computational Engineering, vol. 5, no. 2, pp. 73-82, 2007.

[30] A. Ramazani, K. Mukherjee, H. Quade, U. Prahl, and W. Bleck, "Correlation between 2D and 3D flow curve modelling of DP steels using a microstructure-based RVE approach," Materials Science and Engineering: A Structural Materials: Properties, Microstructure and Processing, vol. 560, pp. 129-139, 2013.

[31] R. Pucha, "RVE-based design and analysis tools for composite materials with nanofillers," Journal of Composite Materials, 2013.

[32] M. B. Wold, L. D. Connell, and S. K. Choi, "The role of spatial variability in coal seam parameters on gas outburst behaviour during coal mining," International Journal of Coal Geology, vol. 75, no. 1, pp. 1-14, 2008.

[33] I. L. Chuanliang and S. Zhu, "Compressibility coefficients of bulk volume and fluid-solid of rocks," Lithologic Reservoirs, vol. 27, no. 2, pp. 1-5, 2015.

[34] W. Murphy, A. Reischer, and H. Kai, "Modulus decomposition of compressional and shear velocities in sand bodies," Geophysics, vol. 58, no. 2, pp. 227-239, 1993.

[35] Q. G. Liu and T. D. Tan, "Identifying lithological characteristics and the type of pore fluid in line of elastic moduli," Geophysical Prospecting for Petroleum, vol. 32, no. 2, pp. 88-96, 1993.

[36] X. W. Qiao and S. W. Yan, "Evaluation of the characteristics of pore fluids in permeable formations using acoustic logging date," WLT, vol. 21, no. 3, pp. 61-66, 1997.

[37] K. Huang, Z. Q. Xu, and H. X. Yang, "The relationship between P- and S- wave velocity ratio, modulus of elasticity and fluids contained in rocks," XJPG, vol. 19, no. 5, pp. 20-22+85, 1998 .

[38] Q. Liu, R. Y. Lu, and X. Z. Li, "The Effect of the Pore Water Pressure on the Rock Mechanics Parameters," Acta Geoscientia Sinica, vol. 29, no. 5, pp. 660-664, 2008.

[39] J. D. Eshelby, "The determination of the elastic field of an ellipsoidal inclusion, and related problems," Proceedings of the Royal Society London A: Mathematical, Physical and Engineering Sciences, vol. 241, pp. 376-396, 1957.

[40] G. J. Rodin, "Eshelby's inclusion problem for polygons and polyhedra," Journal of the Mechanics and Physics of Solids, vol. 44, no. 12, pp. 1977-1995, 1996.
[41] C. Q. Ru, "Eshelby's problem for two-dimensional piezoelectric inclusions of arbitrary shape," Proceedings of the Royal Society A Mathematical, Physical and Engineering Sciences, vol. 456, no. 1997, pp. 1051-1068, 2000.

[42] W. Zou, "Limitation of average eshelby tensor and its application in analysis of ellipse approximation," Acta Mechanica Solida Sinica, vol. 24, no. 2, pp. 176-184, 2011.

[43] M. Kawashita and H. Nozaki, "Eshelby tensor of a polygonal inclusion and its special properties," Journal of Elasticity: The Physical and Mathematical Science of Solids, vol. 64, no. 1, pp. 71-84, 2001.

[44] T. Mori and K. Tanaka, "Average stress in matrix and average elastic energy of materials with misfitting inclusions," Acta Metallurgica et Materialia, vol. 21, no. 5, pp. 571-574, 1973.

[45] A. Giraud, Q. V. Huynh, D. Hoxha, and D. Kondo, "Application of results on Eshelby tensor to the determination of effective poroelastic properties of anisotropic rocks-like composites," International Journal of Solids and Structures, vol. 44, no. 11-12, pp. 3756-3772, 2007.

[46] M. Hu, G.-Y. Xu, and S.-B. Hu, "Study of equivalent elastic modulus of sand gravel soil with Eshelby tensor and MoriTanaka equivalent method," Rock and Soil Mechanics, vol. 34, no. 5, pp. 1437-1448, 2013.

[47] H. Ma, C. Yan, and Q.-H. Qin, “Eigenstrain boundary integral equations with local Eshelby matrix for stress analysis of ellipsoidal particles," Mathematical Problems in Engineering, vol. 2014, Article ID 947205, 10 pages, 2014.

[48] Z. Chao, H. Wang, W. Xu, L. Yang, and K. Zhao, "Variation of permeability and porosity of sandstones with different degrees of saturation under stresses," Chinese Journal of Rock Mechanics and Engineering, vol. 36, no. 3, pp. 665-680, 2017.

[49] H. Wang, W. Xu, J. Zuo, J. Shao, and C. Jia, "Evolution law of the permeability and porosity for low-permeability rock based on gas permeability test," Journal of Hydraulic Engineering, vol. 46, no. 2, pp. 208-216, 2015.

[50] H. W. Zhou, P. Wu, and R. Q. Yang, "Damage model of jointed rock mass," Recent Advances in Rock Mechanics, 1989.

[51] H. W. Yang, Study on Coupling Mechanism of Rock and Pore Water under Cyclic Loading, University of Chongqing, 2011.

[52] W. Wei, Z. Tian, and Q. Zhu, "Study of statistical damage constitutive model for rock considering pore water pressure," Chinese Journal of Rock Mechanics Engineering, 2015. 


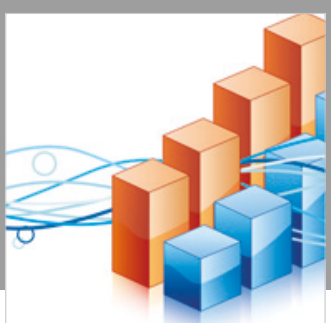

Advances in

Operations Research

\section{-n-m}
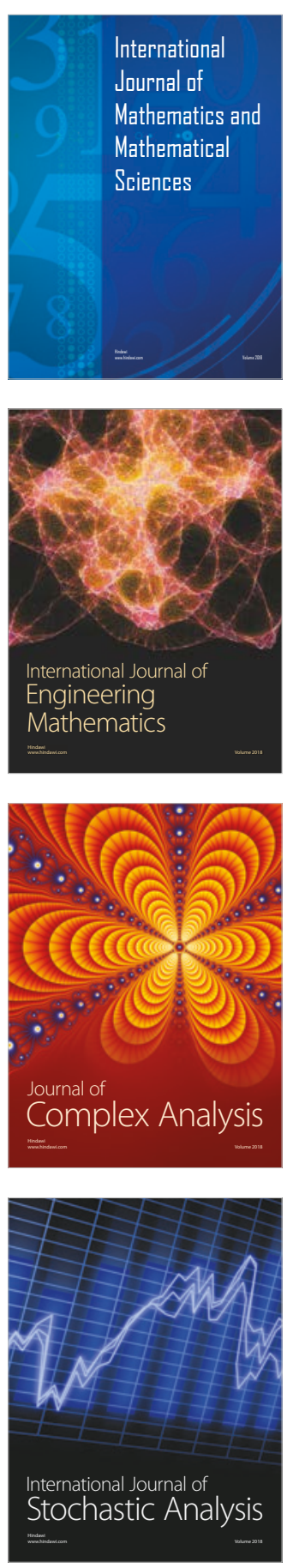
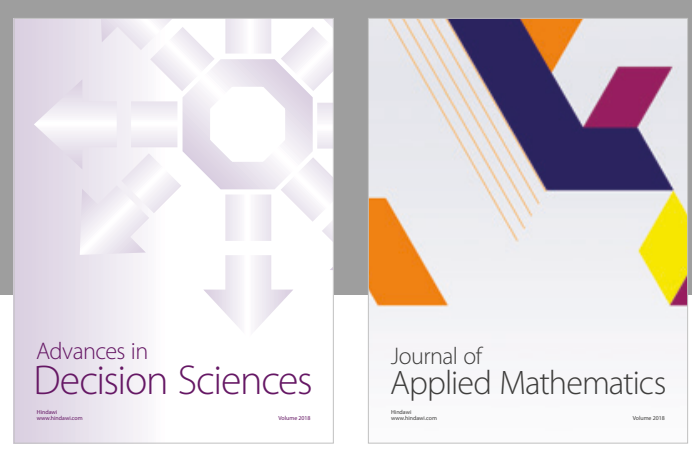

Journal of

Applied Mathematics
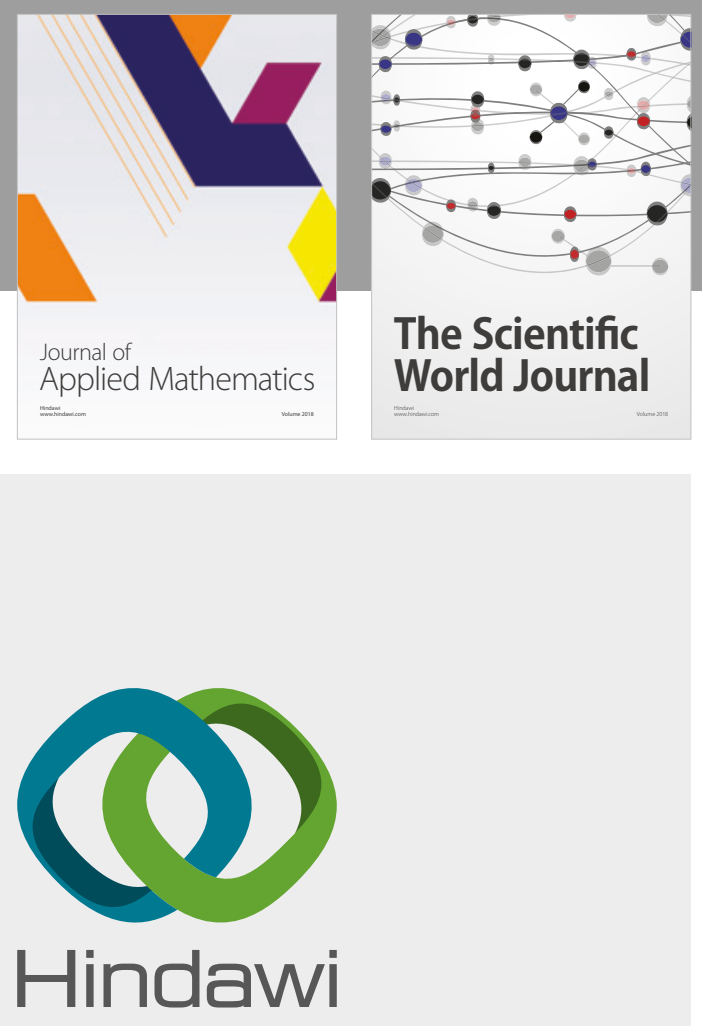

Submit your manuscripts at

www.hindawi.com

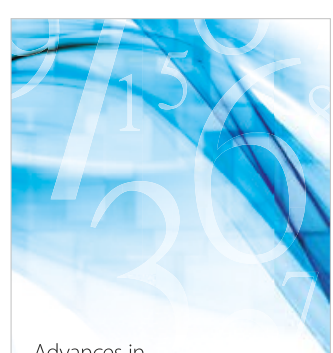

Advances in
Numerical Analysis
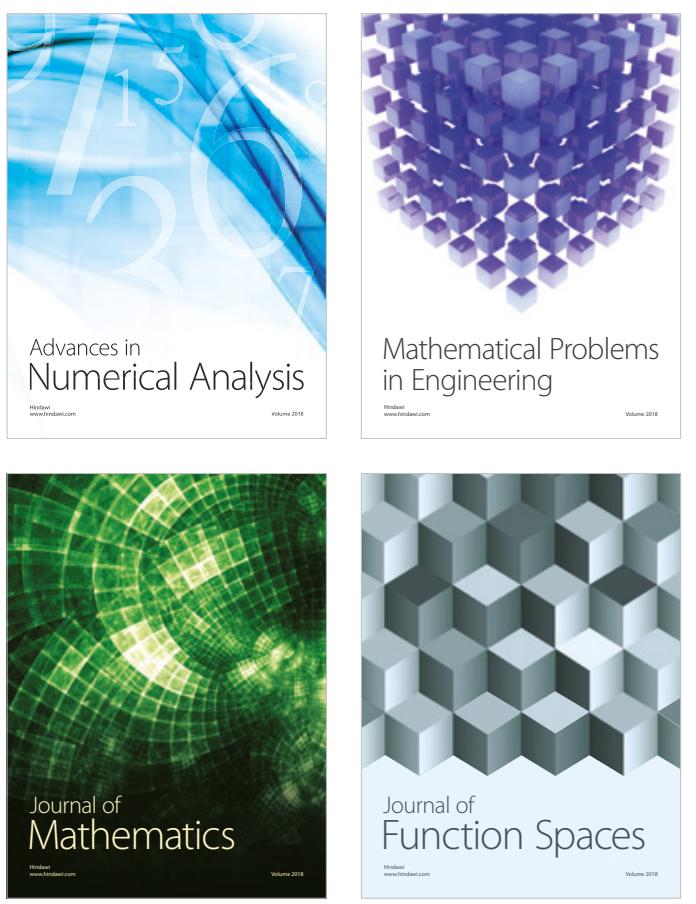

Mathematical Problems in Engineering

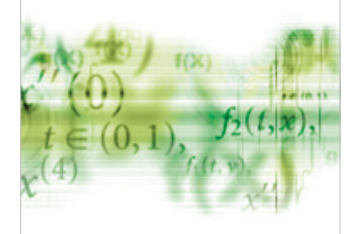

International Journal of

Differential Equations

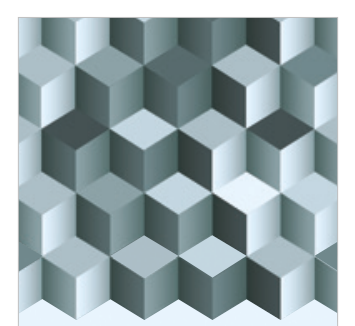

Journal of

Function Spaces

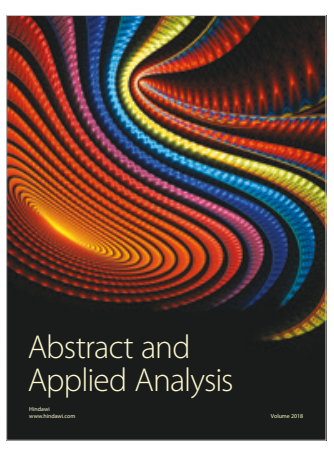

The Scientific

World Journal

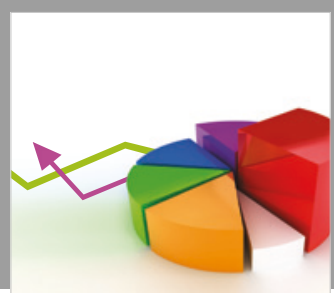

Journal of

Probability and Statistics
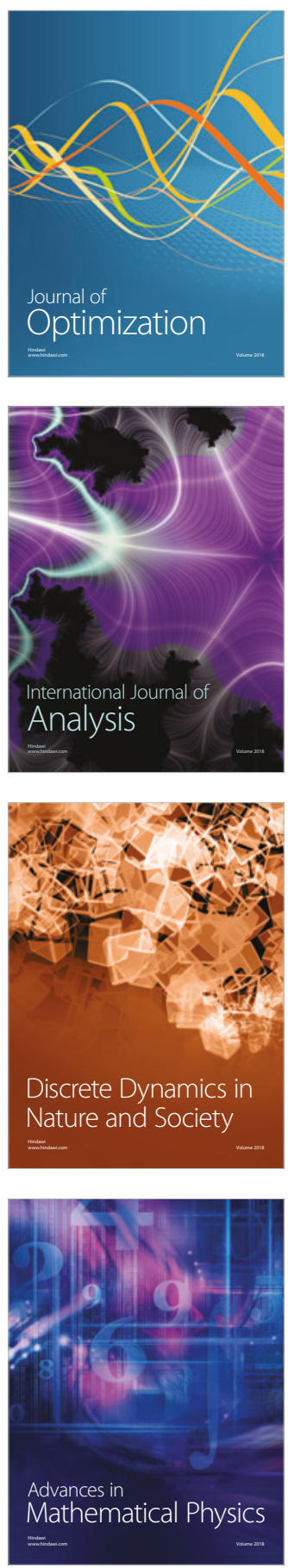